\title{
A rare case of non-invasive ductal carcinoma of the breast coexisting with follicular lymphoma: A case report with a review of the literature
}

\author{
MIKAKO TAMAOKI ${ }^{1}$, YOSHINORI NIO $^{1}$, KAZUHIKO TSUBOI $^{1}$, MARIKA NIO $^{1}$, \\ MASASHI TAMAOKI $^{1}$ and RIRUKE MARUYAMA ${ }^{2}$
}

${ }^{1}$ Nio Breast Surgery Clinic, Kyoto; ${ }^{2}$ Department of Pathology, Faculty of Medicine, Shimane University, Izumo, Japan

Received July 15, 2013; Accepted January 15, 2014

DOI: 10.3892/ol.2014.1885

\begin{abstract}
The double presentation of breast cancer and follicular lymphoma is extremely rare, and only six cases have previously been reported in the literature. In the present study, a case of synchronous ductal carcinoma in situ (DCIS) of the breast and follicular lymphoma is reported. During an annual breast screening procedure, a 49-year-old female presented with a hard induration under the nipple of the right breast and swelling of a soft lymph node (LN) in the right axilla. Mammography and ultrasonography revealed two lesions in the right breast: One was a tumor with microcalcification, $1.0 \mathrm{~cm}$ in diameter, and the other was a large, crude calcification, $2.5 \mathrm{~cm}$ in diameter. In addition, computed tomography and positron emission tomography revealed swellings of the bilateral axillary (Ax) LN and intra-abdominal para-aortic LN. The patient underwent excisions of the large calcified mass, a micro-calcified tumor and the right AxLN. The pathological and immunohistochemical studies revealed fat necrosis and DCIS of the breast, which was positive for the estrogen receptor and the progesterone receptor, while human epidermal growth factor receptor II protein expression was evaluated as $2+$ and stage was classified as pTis pNO M0, stage 0 . Furthermore, the Ax node was diagnosed as follicular lymphoma, which was positive for cluster of differentiation (CD)20, CD79a, CD10 and B-cell lymphoma (Bcl)-2 protein,
\end{abstract}

Correspondence to: Dr Yoshinori Nio, Nio Breast Surgery Clinic, Hello-Yuai Bldg. 1\&2F, 511 Anenishi-horikawa-cho, Nakagyo-ku, Kyoto 604-8264, Japan

E-mail: nio@star.ocn.ne.jp

Abbreviations: Ax, axillary; $\mathrm{BC}$, breast cancer; CT, computed tomography; DCIS, ductal carcinoma in situ; ER, estrogen receptor; FL, follicular lymphoma; HL, Hodgkin's lymphoma; IDC, invasive ductal carcinoma; LN, lymph node; ML, malignant lymphoma; MMG, mammography; NHL, non-Hodgkin lymphoma; RT, radiotherapy; $\mathrm{SNB}$, sentinel node biopsy

Key words: breast cancer, ductal carcinoma in situ, follicular lymphoma, double malignancies but negative for Bcl-6 protein. The clinical stage was classified as stage III. The patient was administered chemotherapy followed by radiotherapy to the conserved breast. Two years have passed since the surgery, and the patient is disease-free.

\section{Introduction}

The incidence of breast cancer (BC) is extremely high, and malignant lymphoma (ML) is a common malignant disease. It is also well known that $\mathrm{BC}$ is the most frequent secondary malignancy following treatment for Hodgkin's lymphoma (HL), particularly in young females who receive radiotherapy for early-stage HL (1-3). By contrast, the incidence of ML, including HL and non-HL (NHL) as second malignancies following breast conserving surgery and radiotherapy (RT) for $\mathrm{BC}$, is rare $(4,5)$.

Follicular lymphoma (FL) is classified as an NHL, amongst which FL is categorized as a low-grade ML and grows slowly. The incidence of FL is $20-30 \%$ of all ML in Europe and the USA (6), but in Japan it is only $10-15 \%$, although it is increasing (7-9). NHL is rarely observed in the synchronous and metachronous presentation with $\mathrm{BC}$, and the double presentation of $\mathrm{BC}$ and $\mathrm{FL}$ is even rarer; previously, only six cases, including metachronous and synchronous double presentation, have been reported in the literature (10-15). In the present study, a case of synchronous ductal carcinoma in situ (DCIS) of the breast and FL is reported, with a review of the literature.

\section{Case report}

The current study describes the case of a 49-year-old female who had previously undergone bilateral breast augmentation with autologous fatty tissue injection in her youth. Prior to the study, the patient attended yearly breast screening appointments. In the most recent breast screening, the patient exhibited no obvious complaints and a mammography (MMG) examination was performed. In previous MMG examinations, no abnormal findings had been identified. The patient had undergone an autologous fat-tissue transplantation 10 years earlier. On palpation, a hard induration was palpated under the nipple of the right breast, and swelling of a soft lymph node (LN) was also palpated in the right axilla. 


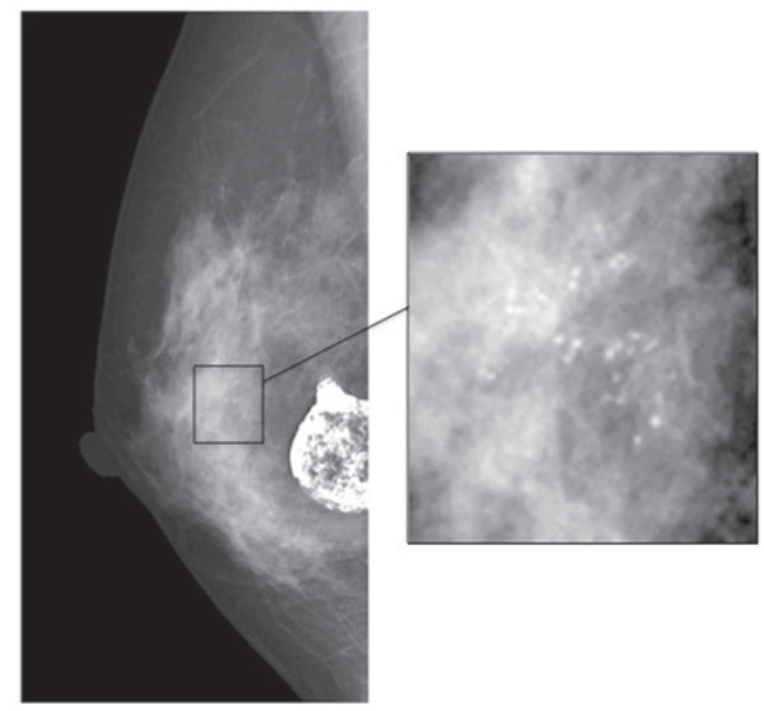

Figure 1. MMG revealing two lesions. As shown in the rectangle, one lesion was grouped as micro-calcifications in a $\sim 1 \mathrm{~cm}^{2}$ area under the right nipple, which was classified as DCIS. Another was a large crude calcification of $2.5 \mathrm{~cm}$ in diameter, which was fat necrosis due to autologous transplantation of fatty tissue in the patient's youth. DCIS, ductal carcinoma in situ; MMG, mammography.
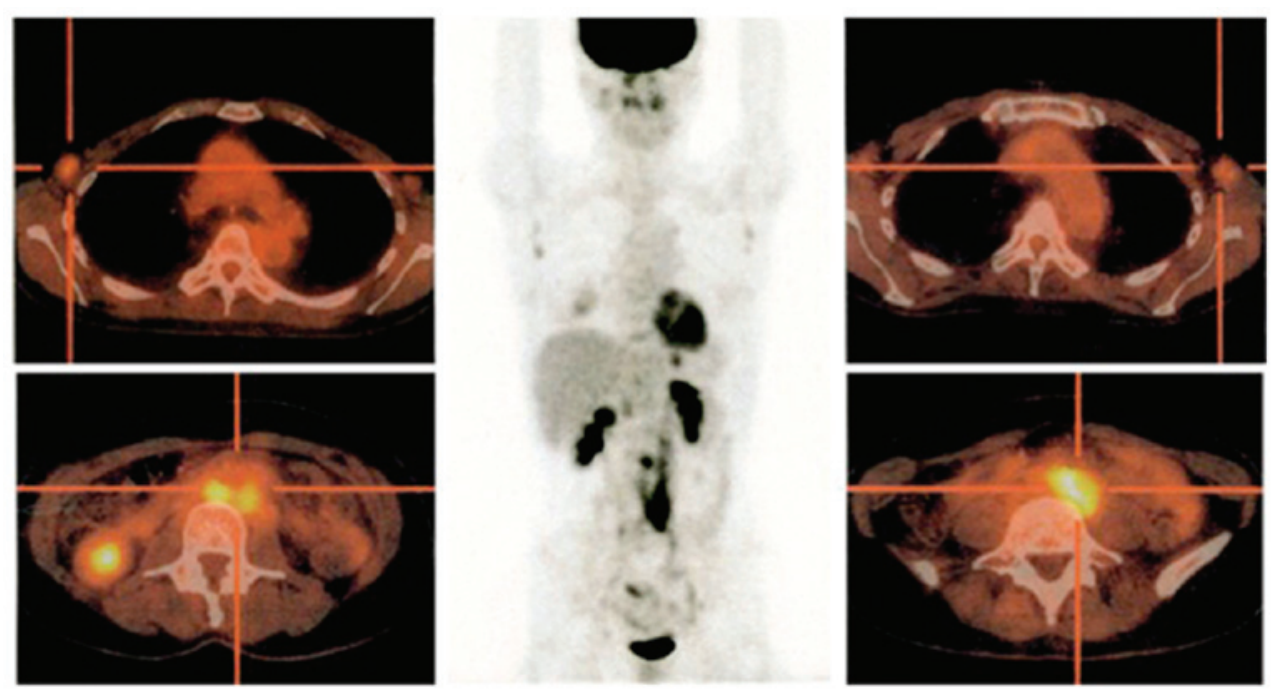

Figure 2. PET demonstrating an accumulation of ${ }^{18} \mathrm{~F}$-fluorodeoxyglucose in the bilateral AxLNs (SUVmax, 2.8) and intra-abdominal para-aortic LNs (SUVmax, 5.8). PET, positron emission tomography; Ax, bilateral axillary; LN, lymph node; SUVmax, maximum standardized uptake value.

An MMG examination revealed two lesions: One consisted of a group of micro-calcifications in a $\sim 1 \mathrm{~cm}^{2}$ area under the right nipple, and the other was a large crude calcification, $2.5 \mathrm{~cm}$ in diameter (Fig. 1). Ultrasonography examination revealed a low echoic lesion, including micro-calcifications and a large calcified mass. The aforementioned examinations indicated DCIS and fat necrosis following autologous fat-tissue transplantation. Computed tomography (CT) examination revealed a crude calcification and a lesion enhanced by a contrast drug. In addition, bilateral axillary (Ax) and intra-abdominal para-aortic LN swelling were revealed. Positron emission tomography (PET) also demonstrated accumulations of ${ }^{18} \mathrm{~F}$-fluorodeoxyglucose in the bilateral AxLNs and intra-abdominal para-aortic LNs (Fig. 2). These findings indicated malignant lymphoma rather than metastasis from the breast DCIS.
The patient underwent excision of the large calcified mass (Fig. 3A), a micro-calcified tumor (Fig. 3B) and the right AxLN. The pathological diagnoses demonstrated that the large calcified mass was fat necrosis and the micro-calcified tumor was DCIS (Fig. 4). For immunohistochemical (IHC) examination, $4-\mu \mathrm{m}$ sections of formalin-fixed, paraffin-embedded specimens were immunostained primarily according to the labeled polymer method using Dako EnVision ${ }^{\mathrm{TM}}$ kit (Dako, Carpinteria, CA, USA), according to the manufacturer's instructions. The primary antibodies were purchased from Roche Diagnostics Japan (Tokyo, Japan) as follows: antiestrogen receptor (ER) rabbit monoclonal antibody ( $\mathrm{mAb}$ ) (SP1), anti-progesterone receptor (PgR) rabbit mAb (1E2) and anti-human epidermal growth factor receptor II (HER2/new) rabbit $\mathrm{mAb}$ and from DakoCytomation (Glostrup, Denmark) as follows: anti-human cluster of differentiation (CD)20 mouse 


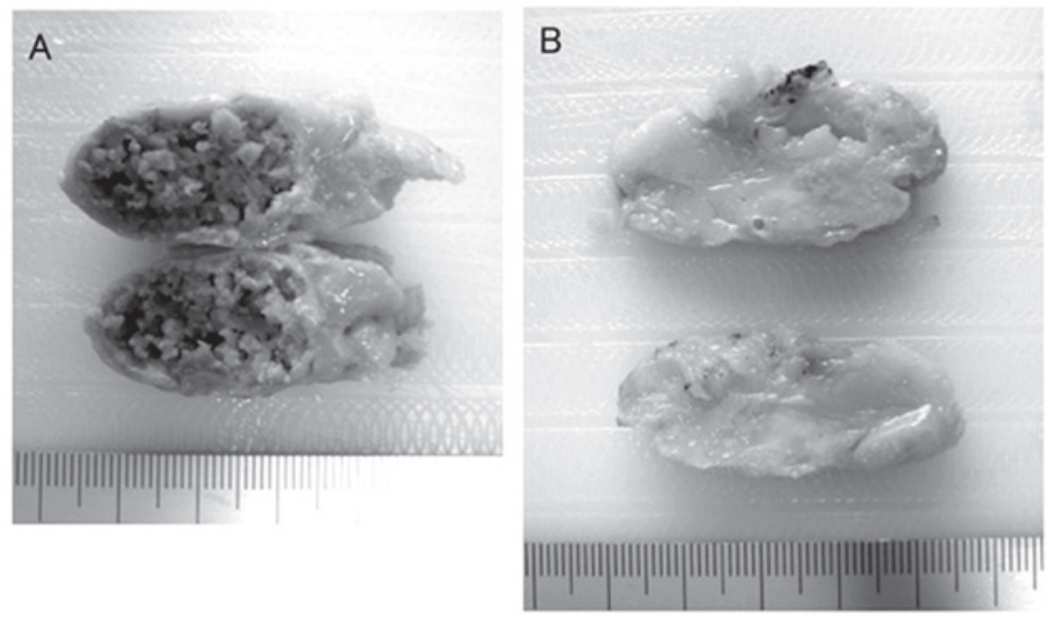

Figure 3. Macroscopic findings of surgical specimens. (A) A large calcified mass of fat necrosis. (B) A micro-calcified tumor of ductal carcinoma in situ (DCIS).

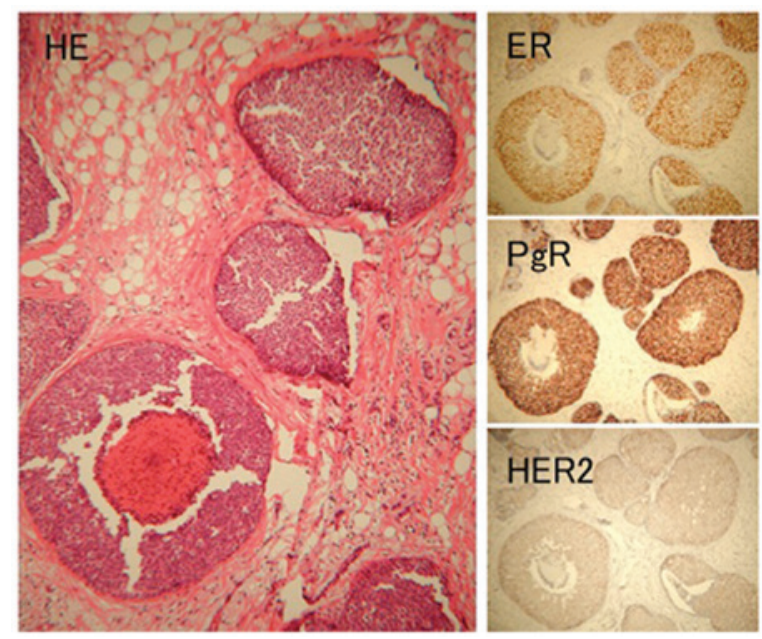

Figure 4. Pathology and immunohistochemistry of the ductal carcinoma in situ (DCIS). Magnification, x100. DCIS was positive for estrogen receptor (ER) and progesterone receptor (PgR), and human epidermal growth factor receptor II (HER2) protein expression was evaluated as $2+$.
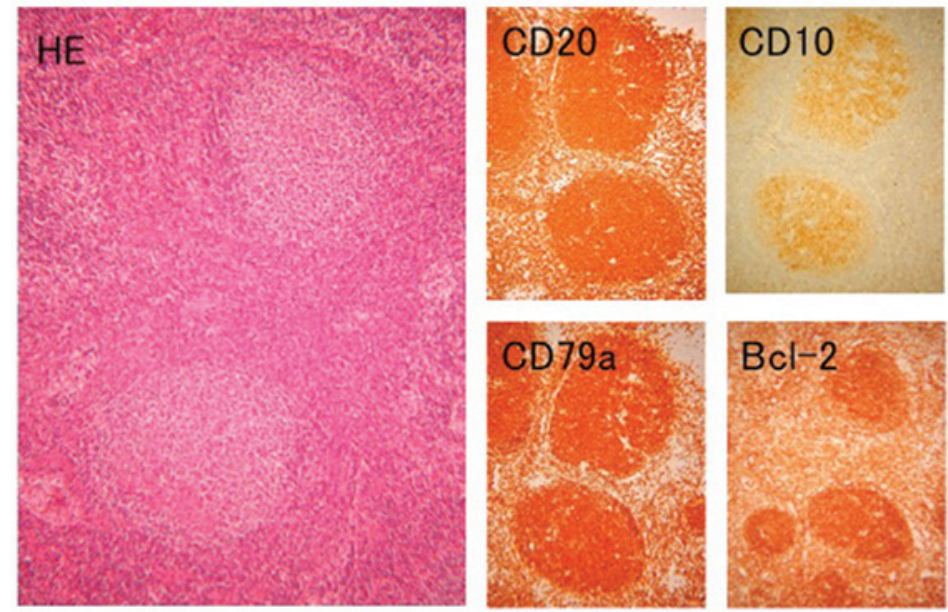

Figure 5. Pathology and immunohistochemistry of FL. Magnification, x100. Tumor cells were positive for CD20, CD79a, CD10 and Bcl-2 protein. FL, follicular lymphoma; $\mathrm{CD}$, cluster of differentiation; Bcl, B cell lymphoma.

$\mathrm{mAb}$, anti-CD79a mouse mAb, anti-CD10 mouse mAb, antiB-cell lymphoma (Bcl)-2 mouse mAb and anti-Bcl-6 mouse $\mathrm{mAb}$. IHC examinations revealed that the DCIS was positive for ER, PR and HER2 protein expression and was evaluated as $2+$. The post-surgical stage classification was pTis pN0 M0, stage 0. The AxLN was diagnosed as FL (Fig. 5), as IHC 
Table I. BC coexisting with FL.

\begin{tabular}{|c|c|c|c|c|c|c|c|}
\hline \multirow[b]{2}{*}{ Characteristics } & \multicolumn{6}{|c|}{ Patient } & \multirow[b]{2}{*}{ Present case } \\
\hline & 1 & 2 & 3 & 4 & 5 & 6 & \\
\hline Age, years & 51 & 61 & 50 & 58 & 52 & 74 & 47 \\
\hline Gender & Female & Female & Female & Female & Female & Female & Female \\
\hline Syn/meta & Metachro & Synchro & Synchro & Synchro & Synchro & Synchro & Synchro \\
\hline \multicolumn{8}{|l|}{$\mathrm{BC}$} \\
\hline Side of Breast & $\mathrm{R}$ & $\mathrm{L}$ & $\mathrm{L}$ & $\mathrm{L}$ & $\mathrm{R}$ & $\mathrm{L}$ & $\mathrm{R}$ \\
\hline Histology & IDC & IDC & IDC & DCIS & IDC & IDC & DCIS \\
\hline Grade & & 2 & 1 & & 2 & 2 & \\
\hline $\mathrm{T}$ & 1 & 1 & 1 & cis & 3 & 1 & cis \\
\hline $\mathrm{N}$ & 0 & 1 & 0 & 0 & 0 & 0 & 0 \\
\hline M & 0 & 0 & 0 & 0 & 0 & 0 & 0 \\
\hline Stage & I & IIA & I & 0 & IIB & I & 0 \\
\hline ER & $(+)$ & & $(+)$ & & $(+)$ & $(+)$ & $(+)$ \\
\hline $\mathrm{PgR}$ & $(-)$ & & $(+)$ & & $(+)$ & $(+)$ & $(+)$ \\
\hline HER2 & & & & & & $(-)$ & $2+$ \\
\hline Surgery & MX & WLE & WLE & MX & MX & WLE & WLE \\
\hline Adjuvant therapy & FT & $\mathrm{RT}+\mathrm{Chem}$ & RT+TAM & None & TAM & $\mathrm{RT}+\mathrm{AI}$ & LP \\
\hline \multicolumn{8}{|l|}{ FL } \\
\hline Biopsy site & $\mathrm{L}-\mathrm{Br}$ & AxLN & AxLN & AxLN & AxLN & AxLN & AxLN \\
\hline Grade & Low & & 1 & Low & & 1 & 1 \\
\hline Stage & & III & IIIA & IA & IA & & III \\
\hline $\mathrm{CD} 20$ & & $(+)$ & $(+)$ & & $(+)$ & $(+)$ & $(+)$ \\
\hline CD23 & & $(+)$ & & & & & \\
\hline CD79a & & & $(+)$ & & & & $(+)$ \\
\hline CD10 & & $(+)$ & $(+)$ & & $(+)$ & $(+)$ & $(+)$ \\
\hline Bcl-2 & & $(+)$ & $(+)$ & & $(+)$ & $(+)$ & $(+)$ \\
\hline Bcl-6 & & & $(+)$ & & & & $(-)$ \\
\hline Cyclin D1 & & & $(-)$ & & & & \\
\hline Therapy & CVP & & $\mathrm{CB}+\mathrm{DM}$ & None & $\mathrm{AC}$ & & R-CVP \\
\hline Reference & 10 & 11 & 12 & 12 & 13 & 14 & \\
\hline Year & 1989 & 2005 & 2006 & 2006 & 2010 & 2010 & 2011 \\
\hline
\end{tabular}

BC, breast cancer; FL, follicular lymphoma; metachro, metachronous; synchro, synchronous; R, right; L, left; Br, breast; IDC, invasive ductal carcinomas; DCIS, ductal carcinoma in situ; T, tumor; N, node; M, metastasis; MX, masectomy; RT, radiotherapy; FT, futraful; Chem, chemotherapy; TAM, tamoxifen; AI, aromatase inhibitor; LP, leuprorelin acetate; Ax, axillary; LN, lymph node; CD, cluster of differentiation; Bcl, B-cell lymphoma; CVP, cyclophosphamide + vincristine + predonosolone; CB + DM, chlorambucil + dexamethasone; AC, adriamycin + cyclophosphamide; R-CVP, rituxan + CVP.

examinations revealed that the tumor cells were positive for CD20, CD79a, CD10 and Bcl-2 protein (Fig. 5), but negative for Bcl-6 protein. The clinical stage was classified as stage III.

Treatment for FL was preferentially continued, as BC is a DCIS. The patient was administered combination chemotherapy with $600 \mathrm{mg}$ rituximab, 1,100 $\mathrm{mg}$ cyclophosphamide, $2 \mathrm{mg}$ vincristine and $80 \mathrm{mg}$ prednisolone (R-CVP) at 3-week intervals for 6 cycles, and the clinical response was evaluated as a complete response. Subsequent to R-CVP therapy, the patient received radiotherapy (RT) to the conserved breast 25 times at $2.0 \mathrm{~Gy}$. In total, RT was received 5 days a week for 5 weeks (total dose, $50 \mathrm{~Gy}$ ). Subsequent to RT, the patient was administered a luteinizing hormone-releasing hormone agonist, leuprorelin acetate, at $3.75 \mathrm{mg}$ at 4 -week intervals. Two years have passed since the surgery, and the patient is disease-free. The patient provided written informed consent.

\section{Discussion}

Synchronous or metachronous presentations of BC and FL are rare, and to the best of our knowledge, only six cases have previously been reported in the literature (10-14); the present study is the seventh case. Profiles of the seven cases are summarized in Table I. Of the seven cases, only one case was a metachronous 
Table II. Double presentation of BC and NHL.

\begin{tabular}{|c|c|c|c|c|c|c|c|c|c|c|}
\hline \multirow[b]{2}{*}{ Case no. } & \multirow{2}{*}{$\begin{array}{l}\text { Age, } \\
\text { years }\end{array}$} & \multirow[b]{2}{*}{ Gender } & \multicolumn{3}{|c|}{$\mathrm{BC}$} & \multicolumn{3}{|c|}{ NHL } & \multirow[b]{2}{*}{ Ref. } & \multirow[b]{2}{*}{ Year } \\
\hline & & & Side & Histol & Stage & Histol & Biopsy location & Stage & & \\
\hline \multicolumn{11}{|l|}{ Synchro } \\
\hline 1 & 66 & $\mathrm{~F}$ & $\mathrm{R}$ & IDC & $2 \mathrm{~A}$ & BL & AxLN & & 16 & 1990 \\
\hline 2 & 77 & $\mathrm{~F}$ & $\mathrm{~L}$ & IDC & 1 & SLL & AxLN & & 16 & 1990 \\
\hline 3 & 77 & $\mathrm{~F}$ & $\mathrm{R}$ & ILC & 1 & LPL & AxLN & $3 \mathrm{~B}$ & 17 & 1994 \\
\hline 4 & 77 & $\mathrm{~F}$ & $\mathrm{~L}$ & Paget+DCIS & 0 & $\mathrm{BL}$ & AxLN & $1 \mathrm{~A}$ & 17 & 1994 \\
\hline 5 & 83 & M & $\mathrm{L}$ & IDC & & LPL & AxLN & $1 \mathrm{~A}$ & 17 & 1994 \\
\hline 6 & 62 & $\mathrm{~F}$ & $\mathrm{R}$ & IDC & $3 \mathrm{~A}$ & SLL/CLL & AxLN & & 18 & 1997 \\
\hline 7 & 62 & $\mathrm{~F}$ & $\mathrm{~L}$ & IDC & 1 & DLBCL & $\mathrm{R}-\mathrm{Br}$ & & 19 & 2002 \\
\hline 8 & 67 & $\mathrm{~F}$ & $\mathrm{~L}$ & IDC & 1 & MCL & AxLN & 1 & 20 & 2003 \\
\hline 9 & 79 & $\mathrm{~F}$ & $\mathrm{~L}$ & IDC & $2 \mathrm{~A}$ & MZBL & AxLN & & 21 & 2004 \\
\hline 10 & 53 & $\mathrm{~F}$ & $\mathrm{~L}$ & IDC & $2 \mathrm{~A}$ & MALT & AxLN & & 22 & 2006 \\
\hline 11 & 63 & $\mathrm{~F}$ & $\mathrm{~L}$ & IDC & 1 & MCL & AxLN & & 12 & 2006 \\
\hline 12 & 56 & $\mathrm{~F}$ & $\mathrm{~L}$ & ILC & $2 \mathrm{~A}$ & MZBL & AxLN & 4 & 23 & 2008 \\
\hline 13 & 57 & $\mathrm{~F}$ & Bil & IDCx 2 & Both 1 & MZBL & AxLN & & 24 & 2008 \\
\hline 14 & 69 & $\mathrm{~F}$ & $\mathrm{R}$ & IDC & 1 & DLBCL & $\mathrm{R}-\mathrm{Br}$ & & 25 & 2009 \\
\hline 15 & 74 & $\mathrm{~F}$ & $\mathrm{R}$ & IDCx 2 & $2 \mathrm{~B}$ & CLL/SLL & AxLN & 0 & 14 & 2010 \\
\hline 16 & 54 & $\mathrm{~F}$ & $\mathrm{~L}$ & IDC & $2 \mathrm{~A}$ & SLL & AxLN & & 14 & 2010 \\
\hline 17 & 52 & $\mathrm{~F}$ & $\mathrm{~L}$ & IDC & & DLBCL & Nasopharynx & & 26 & 2011 \\
\hline 18 & 87 & $\mathrm{~F}$ & n.d. & IDC & & CLL/SLL & AxLN & & 27 & 2011 \\
\hline 19 & 69 & $\mathrm{~F}$ & n.d. & DCIS & & CLL/SLL & AxLN & & 27 & 2011 \\
\hline 20 & 62 & $\mathrm{~F}$ & n.d. & IDC & & CLL/SLL & AxLN & & 27 & 2011 \\
\hline 21 & 58 & $\mathrm{~F}$ & n.d. & IDC & & CLL/SLL & AxLN & & 27 & 2011 \\
\hline 22 & 67 & $\mathrm{~F}$ & n.d. & IDC & & CLL/SLL & AxLN & & 27 & 2011 \\
\hline \multicolumn{11}{|l|}{ Metachro } \\
\hline 1 & 53 & $\mathrm{~F}$ & n.d. & IDC & n.d. & LPL & Parotid gland & $2 \mathrm{~A}$ & 28 & 1990 \\
\hline 2 & 55 & $\mathrm{~F}$ & $\mathrm{~L}$ & IDC & $2 \mathrm{~B}$ & AILT & Neck LN & 2 & 29 & 2003 \\
\hline 3 & 53 & $\mathrm{~F}$ & $\mathrm{R}$ & IDC & $2 B$ & LPL & & & 15 & 2004 \\
\hline
\end{tabular}

BC, breast cancer; NHL, non-Hodgkin's lymphoma; R, right; L, left; Bil, bilateral; Histol, histology; Synchro, synchronous; metachro, metachronous; F, female, M, male; IDC, invasive ductal carcinoma; DCCIS, ductal carcinoma in situ; BL, B-cell lymphoma; SLL, small lymphocytic lymphoma; LPL, lymphoplasmacytic lymphoma; CLL, chronic lymphocytic leukemia; DLBCL, diffuse large B-cell lymphoma; MCL, mantle-cell lymphoma; MZBL, marginal zone B-cell lymphoma; MALT, B-cell lymphoma of mucosa-associated lymphoid tissue; AILT, angioimmunoblastic T-cell lymphoma; LN, lymph node; Ax, axillary; Br, breast; n.d., no description.

presentation, and the FL occurred two and a half years after the BC. Six cases were synchronous presentations. The BCs of the seven cases included five invasive ductal carcinomas (IDC) and two DCISs; four cases had left-sided BCs and three had right-sided BCs. The surgeries included three mastectomies and four breast-conserving surgeries, and the stages were classified as stage 0 in two cases, stage I in three cases, stage IIA in one case and stage IIB in one case. ER was positive in all five cases that were fully described, and following the surgery, six cases were administered adjuvant therapies.

FL was classified as stage IA in two cases, stage III in three cases and unclear in two cases. The biopsy sites for pathological diagnosis included six AxLNs and one breast. Histological grades were described in five cases and all of them were classified as low grade or grade 1. Surface markers were studied in five cases and all of them were positive for CD20, CD10 and Bcl-2 protein. CD79a was positive in two reported cases and Bcl- 6 protein was positive in the present case, but negative in another case reported. The treatment was described in five cases: The patient of the present case was administered R-CVP, while in the other studies, one patient received $\mathrm{CVP}$, one received $\mathrm{CB}$ and dexamethasone, one received adriamycin and cyclophosphamide and the other patient received no treatment.

The double presentation of $\mathrm{BC}$ and $\mathrm{ML}$ is not so rare, however, the majority are cases of individuals, particularly young females, who exhibit $\mathrm{BC}$ as a secondary malignancy subsequent to RT or chemotherapy for HL (1-3). The double presentation of $\mathrm{BC}$ and NHL is rare and to the best of our knowledge, a total of 32 cases, including the present case, have been reported in the literature (15-29). Besides seven cases with FL, the double presentations of NHL and BC have accounted for 25 cases, including 22 synchronous and three metachronous presentations; the profiles are summarized in Table II. Among them, 
chronic lymphocytic leukemia/small lymphocytic lymphoma were most frequently observed in eight cases.

In the present literature review, in 25 of 32 cases (78\%) of double presentation, NHLs were diagnosed by pathologically examining AxLNs. This indicated that the excisional biopsy of the AxLN is the most important factor for identifying ML presenting with BC. For IDC, there is no problem in terms of the diagnosis of ML, as a sentinel node biopsy (SNB) or Ax dissection are the standard procedures. On the other hand, for DCIS, the diagnosis of ML is not always easy, as SNB of an AxLN is not indicated as a standard procedure for DCIS. However, a previous meta-analysis of SNB in DCIS demonstrated that the estimate for the incidence of SN metastases in a patient with a pre-operative diagnosis of DCIS was $7.4 \%$ compared with $3.7 \%$ in patients with a definitive diagnosis of DCIS alone, which indicated that SNB should be considered in patients with a pre-operative diagnosis of DCIS (30). According to the present literature review, SNB may be indicated in cases of DCIS of the breast when the AxLNs are swelling. Furthermore, pre-operative PET/CT examination, if possible, may also be beneficial in detecting metastasis and in identifying other malignant diseases of the LN.

\section{References}

1. Haberer S, Belin L, Le Scodan R, et al: Locoregional treatment for breast carcinoma after Hodgkin's lymphoma: the breast conservation option. Int J Radiat Oncol Biol Phys 82: e145-e152, 2012.

2. Cutuli B, Kanoun S, Tunon De Lara C, et al: Breast cancer occurred after Hodgkin's disease: clinico-pathological features treatments and outcome: analysis of 214 cases. Crit Rev Oncol Hematol 81: 29-37, 2012.

3. Elkin EB, Klem ML, Gonzales AM, et al: Characteristics and outcomes of breast cancer in women with and without a history of radiation for Hodgkin's lymphoma: a multi-institutional, matched cohort study. J Clin Oncol 29: 2466-2473, 2011.

4. Fowble B, Hanlon A, Freedman G, Nicolaou N and Anderson P: Second cancers after conservative surgery and radiation for stages I-II breast cancer: identifying a subset of women at increased risk. Int J Radiat Oncol Biol Phys 51: 679-690, 2001.

5. Lee KD, Chen SC, Chan CH, et al: Increased risk for second primary malignancies in women with breast cancer diagnosed at young age: a population-based study in Taiwan. Cancer Epidemiol Biomarkers Prev 17: 2647-2655, 2008.

6. No authors listed: A clinical evaluation of the International Lymphoma Study Group classification of non-Hodgkin's lymphoma. The Non-Hodgkin's Lymphoma Classification Project. Blood 89: 3909-3918, 1997.

7. Kadin ME, Berard CW, Nanba $K$ and Wakasa $H$ Lymphoproliferative diseases in Japan and Western countries: Proceedings of the United States - Japan Seminar, September 6 and 7, 1982, in Seattle, Washington. Hum Pathol 14: 745-772, 1983.

8. Katsumata N, Matsuno Y, Nakayama H, et al: Prognostic factors and a predictive model of follicular lymphoma: a 25 -year study at a single institution in Japan. Jpn J Clin Oncol 26: 445-454, 1996

9. Kondo E, Ogura M, Kagami Y, et al: Assessment of prognostic factors in follicular lymphoma patients. Int J Hematol 73: 363-368, 2001.

10. Kobayashi R, Osada T, Hamaguchi M, et al: A carcinoma of the right breast arising after a mastectomy in primary malignant lymphoma of the left breast. Gan No Rinsho 35: 1077-1080, 1989 (In Japanese).

11. Barranger E, Marpeau O, Uzan S and Antoine M: Axillary sentinel node involvement by breast cancer coexisting with $\mathrm{B}$-cell follicular lymphoma in nonsentinel nodes. Breast $\mathrm{J}$ 11: 227-228, 2005
12. Cox J, Lunt L and Webb L: Synchronous presentation of breast carcinoma and lymphoma in the axillary nodes. Breast 15 : 246-252, 2006.

13. Laudenschlager MD, Tyler KL, Geis MC, Koch MR and Graham DB: A rare case of synchronous invasive ductal carcinoma of the breast and follicular lymphoma. S D Med 63: 123-125, 2010.

14. Cuff KE, Dettrick AJ and Chern B: Synchronous breast cancer and lymphoma: a case series and a review of the literature. J Clin Pathol 63: 555-557, 2010.

15. Benoit L, Arnould L, Collin F, Fraisse J, Cuisenier J and Chauffert B: Concurrent lymphoma and metastatic breast carcinoma in the axillary, confounding sentinel lymph-node biopsy. Eur J Surg Oncol 30: 462-463, 2004.

16. Stierer M, Rosen HR, Heinz R and Hanak H: Synchrony of malignant lymphoma and breast cancer. JAMA 263: 2922-2923, 1990.

17. Frey BM, Morant R, Senn HJ, Fisch T and Schmid U: Simultaneous occurrence of breast carcinoma and malignant lymphoma. Case observations and literature review. Schweiz Med Wochenschr 124: 1010-1016, 1994 (In German).

18. Caraway NP, Wojcik EM, Saboorian HM and Katz RL: Concomitant lymphoma and metastatic carcinoma in a lymph node: diagnosis by fine-needle aspiration biopsy in two cases. Diagn Cytopathol 17: 287-291, 1997.

19. Frei KA, Bonel HM, Forrer P, Alleman J and Steiner RA: Primary breast lymphoma, contralateral breast cancer, and bilateral Brenner tumors of the ovary. Obstet Gynecol 100: 1079-1082, 2002

20. Dutta Roy S, Stafford JA, Scally J and Selvachandran SN: A rare case of breast carcinoma co-existing with axillary mantle cell lymphoma. World J Surg Oncol 1: 27, 2003.

21. Susnik B, Jordi Rowe J, Redlich PN, Chitambar C, Chang CC and Kampalath B: A unique collision tumor in breast: invasive ductal carcinoma and mucosa-associated lymphoid tissue lymphoma. Arch Pathol Lab Med 128: 99-101, 2004.

22. Quilon JM, Gaskin TA, Ludwig AS and Alley C: Collision tumor: invasive ductal carcinoma in association with mucosa-associated lymphoid tissue (MALT) lymphoma in the same breast. South Med J 99: 164-167, 2006.

23. Anavekar NS, Rozen WM, Rowe K and Murphy C: Synchronous carcinoma and lymphoma of the breast. Clin Breast Cancer 8: 281-284, 2008.

24. Garg NK, Bagul NB, Rubin G and Shah EF: Primary lymphoma of the breast involving both axillae with bilateral breast carcinoma. World J Surg Oncol 6: 52, 2008.

25. Broco S, Bonito N, Jacinto P, Sousa G and Gervásio H: Primary non-Hodgkin lymphoma and invasive ductal carcinoma in the same breast: a rare case report. Clin Transl Oncol 11: 186-188, 2009.

26. Papajík T, Mysliveček M, Sedová Z, et al: Synchronous second primary neoplasms detected by initial staging F-18 FDG PET/CT examination in patients with non-Hodgkin lymphoma. Clin Nucl Med 36: 509-512, 2011.

27. Wahner-Roedler DL, Reynolds CA and Boughey JC: Collision tumors with synchronous presentation of breast carcinoma and lymphoproliferative disorders in the axillary nodes of patients with newly diagnosed breast cancer: a case series. Clin Breast Cancer 11: 61-66, 2011.

28. Kohno A, Kohriyama K and Arimori S: Breast cancer and B cell malignant lymphoma associated with Sjögren's syndrome - a case report and review of literature in Japan. Ryumachi 30: 388-395, 1990 (In Japanese).

29. Nagasaki E, Furuta N, Shinozaki E, et al: Simultaneous detection of both non-Hodgkin's lymphoma cells and breast cancer cells in pleural effusion - a case report. Gan To Kagaku Ryoho 30: 1523-1527, 2003 (In Japanese).

30. Ansari B, Ogston SA, Purdie CA, Adamson DJ, Brown DC and Thompson AM: Meta-analysis of sentinel node biopsy in ductal carcinoma in situ of the breast. Br J Surg 95: 547-554, 2008. 